\title{
The effect of granular activated carbon on the physical properties of soils at copper contamination
}

\author{
Inna Zamulina ${ }^{1, *}$, David Pinsky ${ }^{2}$, Marina Burachevskaya ${ }^{1}$, Tatiana Bauer $^{3}$, Alena \\ Pshenichnaya $^{1}$ \\ ${ }^{1}$ Southern Federal University, 194/1, prosp. Stachki, 344090,Rostov-on-Don, Russia \\ ${ }^{2}$ Institute of Physicochemical and Biological Problems of Soil Science, Russian Academy of \\ Sciences, 2, st. Institutskaya, 142290, Pushchino, Russia \\ ${ }^{3}$ Federal Research Center the Southern Scientific Center of the Russian Academy of Sciences, 41, st. \\ Chehova, 344006, Rostov-on-Don, Russia
}

\begin{abstract}
In this study, the effect of granular activated carbon on the physical properties of soils containing copper pollution was presented. The result showed activated carbon could exert a positive effect on accelerating the process of restoring the physical properties of the soil, due to the high porosity and the specific surface area. The soil after remediation with the activated carbon showed better structural state and more water-holding capacity.
\end{abstract}

\section{Introduction}

The prospects for the widespread use of carbon sorbents for soil pollution remediation are being extensively investigated due to their corresponding effect on soil properties. Their introduction into the soil can lead to an increase in the water-holding capacity of soil by an average of $6-15 \%[1,2]$. Possessing high porosity $(70-80 \%)$ and low elasticity, carbon sorbents become a focus of research for avoiding soil aggregation, improving the total porosity [3, 4], and increasing the resistance of soils against mechanical loads [1]. In addition to a direct effect on chemical and physical soil properties, an indirect effect is also reported due to microbiota activation and their involvement in biochemical processes within the soil medium.

Carbon sorbents such as granular activated carbon (GAC) are widely used, their world production reaches hundreds of thousands of tons per year [5]. The commercial availability in the market and the ease of use and operation motivate many researchers to assess their impact on the physical properties of soils.

\section{Materials and Methods}

In this regard, a model vegetation experiment was designed. The upper layer $(0-20 \mathrm{~cm})$ of

\footnotetext{
*Corresponding author: ivzamulina@sfedu.ru
} 
Haplic chernozem of the specially protected natural area "Persianovskaya steppe" located far from possible sources of pollution was selected. 2-liter vegetation vessels with a closed drainage system were used. The vessels were poured with $2 \mathrm{~kg}$ of soil passed through a sieve with the opening of $2 \mathrm{~mm}$ diameter. Afterward, $\mathrm{Cu}$ was introduced in the form of metal oxide (in a dry state, layer by layer, thoroughly mixed) at doses of 300 and 2000 $\mathrm{mg} / \mathrm{kg}$. For 2 months, GAC was added to contaminated soil at doses of $1 \%$ and $2.5 \%$. The characterization was done at GAC samples to detect $\mathrm{Cu}$. No $\mathrm{Cu}$ was detected in bare GAC samples. The soil was incubated for 4 months at a water content of $60 \%$ of the total field capacity and the temperature range between $20-22^{\circ} \mathrm{C}$. The scheme of model vegetative experiment was as follows 1) Control; 2) Control $+1 \%$ GAC; 3 ) Control $+2.5 \%$ GAC; 4) $\mathrm{Cu} 300 \mathrm{mg} / \mathrm{kg}$; 5) Cu 2,000 mg/kg; 6) Cu $300 \mathrm{mg} / \mathrm{kg}+1 \%$ GAC; 7) $\mathrm{Cu} 300 \mathrm{mg} / \mathrm{kg}+2.5 \%$ $\mathrm{GAC}$; 8) $\mathrm{Cu} 2,000 \mathrm{mg} / \mathrm{kg}+1 \% \mathrm{GAC}$; 9) $\mathrm{Cu} 2,000 \mathrm{mg} / \mathrm{kg}+2.5 \% \mathrm{GAC}$.

After 4 months of incubation, two-row spring barley (Hordeum sativum distichum) of the Ratnik variety was seeded. Watering was carried out every other day in order to maintain the corresponding humidity at field moisture capacity $(60 \%)$. Soil properties were determined according to the method suggested by Standard Methods. The particle size distribution was determined by the pipette method (PM) (with pyrophosphate procedure of soil preparation) and laser diffraction (LD). The structural state of soils was analyzed by the Savvinov method of dry and wet sieving without the soil crushing [6]. The moisture absorption capacity of the sorbents was measured by water saturation, evaluated in $\%$ of the air-dry mass. To study water holding capacity, the amount of evaporated moisture was measured every 12 hours at a temperature of $22-23^{\circ} \mathrm{C}$. Bottles with saturated samples of Haplic Chernozem, GAC, and sand were placed in the climatic chamber. The amount of water at the initial stage was the same for all samples. Each experiment was performed in triplicate.

\section{Results and Discussion}

The particle size distribution of Haplic Chernozem according to the classification of N.A. Kachinsky was established to correspond to a heavy loam variety. The content of physical clay in the control samples was $48.1 \%$. The predominant fraction was silt $-28.6 \%$. The soil texture analysis by the LD method showed a lower content of silt fraction (not more than $6 \%$ ). This is the main difference between the results, which has been extensively discussed in detail [7].

The distribution of particle size fractions varied slightly according to the experimental variants (Figure 1). In natural undisturbed soils, particles are sorted by shape and size naturally and this property is quite stable. However, particle size distribution on experimental variants underwent changes by the addition of pollutant and GAC.

Various analysis methods employed in this study resulted in different particle size compositions. PM demonstrated a change in fractions smaller than $0.01 \mathrm{~mm}$ for the experimental variants, while the LD analysis showed the main differences in the fractions of fine sand (0.05-0.25 mm) and coarse dust (0.01-0.05 mm) (Figure 1). These differences were due to the features of the methods, which have a completely different physical basis. PM is based on the sedimentation phenomenon and Stokes law, the reported result is shown on a mass-based distribution of particles. In contrary to PM, LD involves the scattering of electromagnetic waves [7].

As shown by LD, the application of sorbents did not significantly affect the fraction distribution. The introduction of a new solid-phase component with different particle sizes into the system resulted in the redistribution of the fractional composition mainly due to fine sand and coarse dust (Figure 1). 

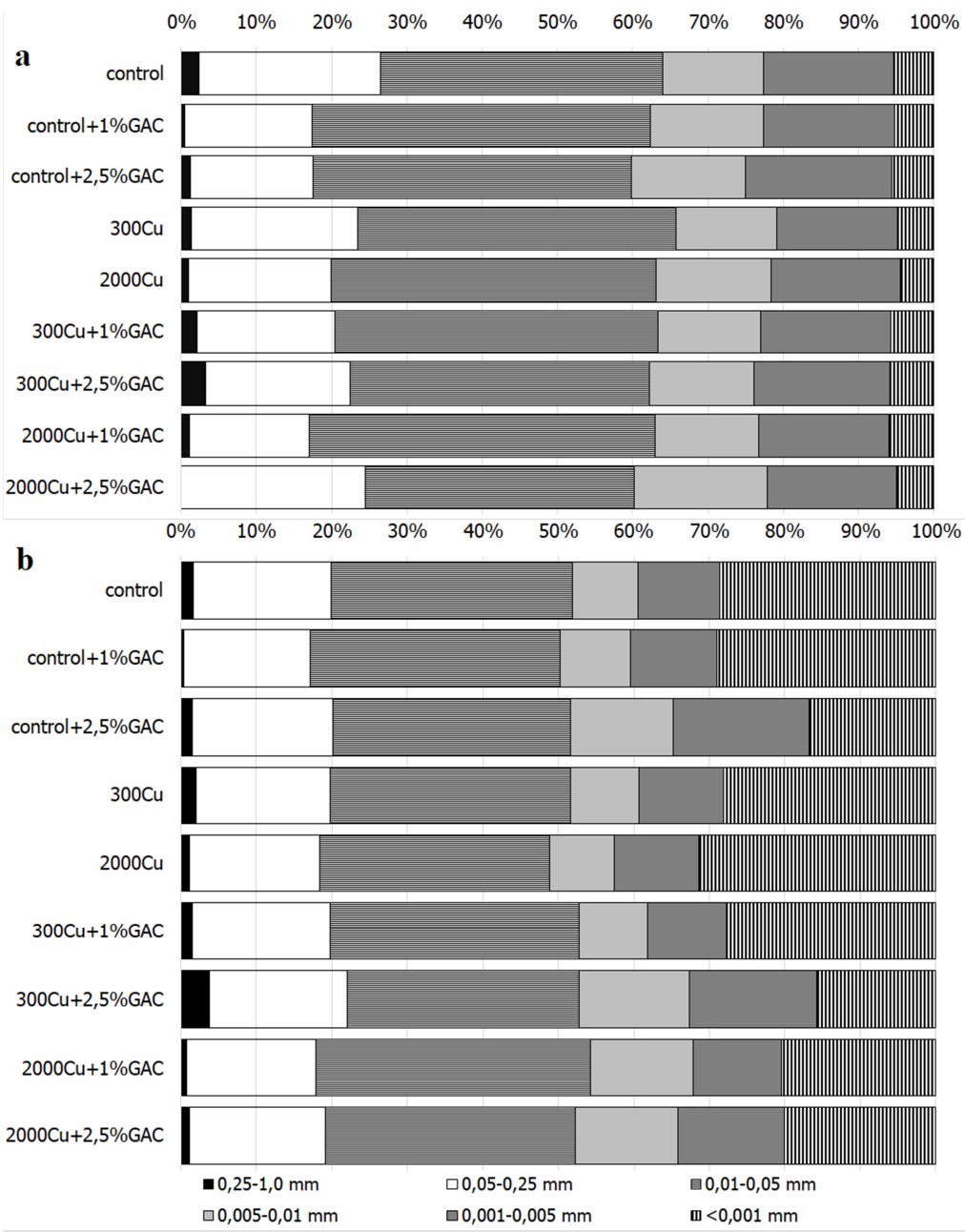

Fig. 1. Particle size composition in Haplic Chernozem under contamination with 300 and $2000 \mathrm{mg} / \mathrm{kg}$ $\mathrm{Cu}$ and $\mathrm{GAC}$ in doses of $1 \%$ and $2.5 \%$ : a - data obtained by the laser diffraction method, $\mathrm{b}$ - data obtained by the pipette method (PM).

The change in the particle size composition determined by PM could be accounted for several reasons, including a change in solid-phase density [6], silt particles flocculation and dehydration of the interlayer zones of minerals with an expanding crystal lattice [8], the effect of $\mathrm{Cu}$ on double electric layer thickness [9], the formation of metal-organic complexes with heavy metal cations (HM) and partial destruction of organomineral compounds [4], and new component introduction.

The soil structure plays an important role in its properties and environmental functions [10]. During the greenhouse experiment, soil aggregates were seen in all experimental variants, although, their quantity and quality were different. The results of dry sieving showed an increase in agronomically valuable aggregates formed in variants with GAC introduction at doses of $1 \%$ and $2.5 \%$ compared with the control. According to the structure assessment scale proposed by S.I. Dolgov and P.U. Bakhtin [11], the state changed from good to excellent. The maximum number of aggregates $(0.25-10 \mathrm{~mm}$ in size $)$ was formed when GAC was introduced at a dose of $2.5 \%-82 \%$. The introduction of $\mathrm{Cu}$ reduced the number of agronomically valuable aggregates to $72 \%$ under dry sieving (by $6 \%$ compared 
with the control) (Table 1). With an increase in the content of HM, a decrease in the waterresistance of aggregates was detected [6]. The absorption of $\mathrm{Cu}^{2+}$ ions by soil adsorption complex is largely carried out by the ion exchange mechanism, and the replacement of $\mathrm{Ca}^{2+}$ and $\mathrm{Fe}^{2+}$ ions with $\mathrm{HM}$ cations can significantly affect the water-resistance of the corresponding aggregates [6]. Water-resistance increases with the increase in the number of aggregates more than $0.25 \mathrm{~mm}$ in size. The results of wet sieving suggest that the differences in the number of water-resistant aggregates were insignificant and most of the experimental variants felt into the assessment level of good. The exception is variant with the introduction of $\mathrm{Cu}$ at a dose of $2000 \mathrm{mg} / \mathrm{kg}$ and the combined introduction of $\mathrm{Cu}$ and $\mathrm{GAC}$ at a dose of $1 \%$. Despite the fact that the number of water-resistant aggregates increased by $7 \%$ compared with the contaminated variant, this dose was probably not enough to overcome the negative effect. Crushing of humic acids upon interaction with HM cations has been experimentally proved [12]; as a result, a part of the organic matter, which plays the role of structure-forming agents, is removed from the composition of the solid phase and the aggregates disintegrate. GAC, having a high porosity and a specific surface, can act as an aggregation core linking clay minerals and organic matter [13].

The introduction of highly porous carbon sorbents causes the decrease in the soil bulk density, an increase in porosity and water holding capacity $[1,4]$. GAC water holding is $181 \%$, which is more than 2 times higher than in the soil of the control variant $(70 \%)$. The introduction of a highly porous sorbent, which leads to high sorption ability, will increase the water holding capacity of soils [4].

Table 1. Assessment of the structure of Haplic Chernozem under contamination of 300 and 2000 $\mathrm{mg} / \mathrm{kg} \mathrm{Cu}$ and the introduction of GAC in doses of $1 \%$ and $2.5 \%$.

\begin{tabular}{|l|c|c|c|c|}
\hline \multirow{2}{*}{$\begin{array}{c}\text { Experimental } \\
\text { treatments }\end{array}$} & \multicolumn{2}{|c|}{$\begin{array}{c}\text { The aggregate content } \mathbf{( 0 . 2 5 -} \\
\mathbf{1 0 . 0} \mathbf{~ m m}) \mathbf{\%}\end{array}$} & \multicolumn{2}{c|}{$\begin{array}{c}\text { The agroecological estimation of } \\
\text { the structural state (Dolgov. } \\
\text { Bahktin 1966) }\end{array}$} \\
\cline { 2 - 5 } & $\begin{array}{l}\text { dry sieving } \\
\text { method }\end{array}$ & $\begin{array}{l}\text { wet sieving } \\
\text { method }\end{array}$ & $\begin{array}{c}\text { dry sieving } \\
\text { method }\end{array}$ & $\begin{array}{c}\text { wet sieving } \\
\text { method }\end{array}$ \\
\hline control & $78 \pm 0.5$ & $58 \pm 0.8$ & good & good \\
\hline control+1\%GAC & $81 \pm 0.6$ & $60 \pm 1.0$ & excellent & good \\
\hline control $+2.5 \% \mathrm{GAC}$ & $82 \pm 0.2$ & $65 \pm 0.9$ & excellent & good \\
\hline $300 \mathrm{Cu}$ & $78 \pm 0.5$ & $55 \pm 0.5$ & good & good \\
\hline $2000 \mathrm{Cu}$ & $72 \pm 0.4$ & $47 \pm 0.9$ & good & satisfactory \\
\hline $300 \mathrm{Cu}+1 \% \mathrm{GAC}$ & $80 \pm 0.3$ & $56 \pm 0.5$ & excellent & good \\
\hline $300 \mathrm{Cu}+2.5 \% \mathrm{GAC}$ & $77 \pm 0.7$ & $65 \pm 1.2$ & good & good \\
\hline $2000 \mathrm{Cu}+1 \% \mathrm{GAC}$ & $71 \pm 1.2$ & $54 \pm 0.8$ & good & satisfactory \\
\hline $2000 \mathrm{Cu}+2.5 \% \mathrm{GAC}$ & $79 \pm 0.1$ & $66 \pm 0.9$ & good & good \\
\hline
\end{tabular}

Evaporation curves showed that with the same amount of moisture, the time required for the accomplishment of drying was different. The sand completely lost moisture on the second day of the experiment, while GAC required 96 hours. It took about 72 hours for the control soil to lose moisture (Figure 2). Moisture evaporation with the GAC addition would proceed more slowly, which is very important in conditions of unstable humidification and an arid climate. The complete moisture loss by GAC during evaporation suggests that the water adsorbed on the surface could be readily available to plants. 


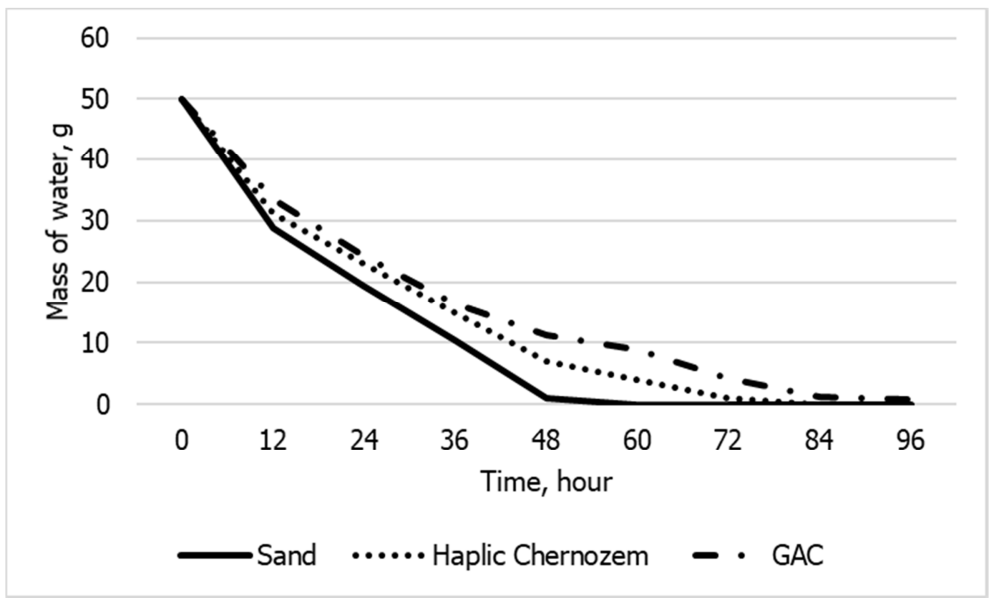

Fig. 2. Water evaporation rate of GAC and Haplic Chernozem compared to sand.

\section{Conclusions}

Thus, $\mathrm{Cu}$ pollution of Haplic Chernozem could have not only a direct toxicological effect but also could lead to a deterioration of physical indicators. The use of GAC had a positive effect on accelerating the process of restoring the physical properties of the soil and hence improving its quality. The high porosity and the large specific surface area of the carbon sorbent contribute to an improvement in the soil structure and an increase in water holding capacity.

\section{Acknowledgments}

The reported study was funded by RFBR, projects numbers 19-29-05265, 19-34-60041, Grant of President of Russian Federation no. MK-2244.2020.5

\section{References}

1. E.Y. Rizhiya, N.P. Buchkina, I.M. Mukhina, A.S. Belinets, E.V. Balashov, Eur. Soil Sci. 48, 192-200 (2015) doi: 10.1134/S1064229314120084

2. D.N. Dempster, D.L. Jones, D.V. Murphy Soil Biol. Biochem. 48, 47-50 (2012) doi: 10.1016/j.soilbio.2012.01.013

3. S.P. Sohi, E. Lopez Capel, R. Bol, E. Krull, Advances in Agronomy 105, 47-82 (2010) doi: 10.1016/S0065-2113(10)05002-9

4. Y. Hamid, L. Tang, B. Hussain, M. Usman, Q. Lin, M. S. Rashid, Z. He, X. Yang, Sci. Total Environ. 13612 (2019) doi: 10.1016/j.scitotenv.2019.136121

5. D. Eeshwarasinghe, P. Loganathan, S. Vigneswaran, Chemosphere 223, 616-627 (2019) doi: 10.1016/j.chemosphere.2019.02.033

6. T.M. Minkina, D.L. Pinskii, I.V. Zamulina, D.G. Nevidomskaya, C. Gülser, S.S. Mandzhieva, T.V. Bauer, I.V. Morozov, S.N. Sushkova, R. Kizilkaya, J. Soils Sediments 18(6), 2418-2430 (2018) doi: 10.1007/s11368-017-1713-5

7. A.V. Yudina, D.S. Fomin, A.D. Kotelnikova, E.Y. Milanovskii, Eur. Soil Sci. 51(11), 1326-1347 (2018) doi: 10.1134/S1064229318110091 
8. R.V.P. Chavali, H.P.R. Ponnapureddy, J. Int. J. Geotech. Eng. 12(5), 500-506 (2018) doi: 10.1080/19386362.2017.1299418

9. B. Bate, S.E. Burns, Can. Geotechnol. J. 51(7), 782-794 (2014) doi: 10.1139/cgj-20130286

10. T. Dorji, D.J. Field, I.O.A. Odeh, Soil Use Manage (2019) doi: 10.1111/sum.12549

11. O.S. Bezuglova, S.S. Tagiverdiev, S.N. Gorbov, Eur. Soil Sci. 51(9), 1105-1110 (2018) doi: 10.1134/S1064229318090028

12. I.P. Makarychev, G.V. Motuzova, Moscow Univ. Soil Sci. Bull. 68, 41-47 (2013) doi:10.3103/S0147687413010055

13. H. Zheng, X. Wang, X.X. Luo, Z.Y. Wang, B.S. Xing, Sci. Total Environ. 610, 951960 (2018) doi: 10.1016/j.scitotenv.2017.08.166 